\title{
Smart Clothline System Based on Internet of Thing (loT)
}

\author{
*Zakiah Mohd Yusoff', *, Zuraida Muhammad², Amar Faiz Zainal Abidin ${ }^{3}, K A$ Nur \\ Dalila $^{1}$, Noor Fadzilah Razali ${ }^{1}$, Masmaria Abdul Majid ${ }^{1}$, KK. Hasan ${ }^{1}$ \\ ${ }^{1}$ Faculty of Electrical Engineering, Universiti Teknologi MARA, 81750 Masai, Johor,Malaysia \\ ${ }^{2}$ Faculty of Electrical Enigneering, Universiti Teknologi MARA, Pulau Pinang,Malaysia \\ ${ }^{3}$ Faculty of Electrical, Universiti Teknikal Malaysia Melaka, Hang Tuah Jaya, 76100 Durian Tunggal, \\ Melaka, Malaysia
}

\begin{abstract}
Along with the growth of economic and infrastructure development, the level of invention or technologies is increasing steadily. These modern technology or invention is very useful to help people ease their daily life. Nowadays, there are many new inventions that have been developed due to the people demands. This is supported by the development of new technologies. This is because people nowadays are busy with their household management or have long working hours that makes they do not have enough time to do all home works such as pick up their clothes at their cloth line. To handle this problem, an Internet of Thing (IoT) Smart Cloth Line is one of the solutions. In this project, a smart cloth line is used to avoid the clothes from moistened with rainwater. When rain falls, the mechanical parts of cloth line will compress and expand when rains stop. The cloth line consists of Arduino UNO microcontroller, rain sensor, LDR, temperature and humidity sensor, servo motor and LCD display. During rainy day, the rain sensor will detect the present of water and servo motor will compress the mechanical parts of the cloth line. This is also an IoT based project so when anything happens when it is raining, it will automatically send notification to the user smartphone. The users also can get notification of temperature, humidity and intensity of light around their cloth line. Obviously, this project can help people in their daily life.
\end{abstract}

\section{Introduction}

Nowadays, housing is one of the important needs of society. In the modern world and better economic situation, the demands of having a safe and comfortable home is increasing rapidly for many people in urban areas since most of the people turning to technology in order to improving the daily life $[1,2]$. The main purpose of smart home is to make sure homeowners can create comfort and safe when they inside or outside the house beside the home is built friendly to the environment, preventing social problems, how space it uses, or energy efficiency, maintaining privacy and recycling waste water[1, 2]. An intelligent smart home system has their own computer system which is able to monitor many aspects of daily

\footnotetext{
* Corresponding author: zakiah9018@johor.uitm.du.my
} 
life. It's consist of home appliances, sensors, actuators, analyser, data processors [3] and can be applied either by wired or wireless[4].

The Internet of Things (IoT) is a device that connected to the network by any location within the globe that can be monitored and controlled remotely by user[5, 6]. The IoT that was first introduced by Kevin Ashton in 1999 is not something new since there are various implementation in many years ago in many places[2, 7, 8]. For example, [1] developed as smart home based on Raspberry PI and Android mobile device to manage smart home behaviour by easy to implement, flexible and scalable solution. The Development of Energy Saving Smart Home Prototype by Panna [9] developed an IoT smart home prototype using PIC18F458 microcontroller with the purposed to save electricity. Besides that, Piyare and Song built "Smart Home-Control and Monitoring System Using Smart Phone" to control and monitoring using micro-web server and smartphones. This work used an Arduino as a main controller to transmit data from the sensor to mobile user[10]. In IoT smart home development, there are many types of microcontroller that was implemented such as Arduino Uno, Arduino Mega, Raspberry PI, Global System for Mobile (GSM) and NodeMCU.[1, 2, $5,10-12]$.

\section{Methodologies}

This project consists of 3 major parts: Hardware, Software and Simulation parts.

\subsection{Hardware Design}

The system hardware consists of three main modules which are sensing module, controller module and output module.

Figure 1 shows the overall block diagram for IoT Smart Cloth Line system. The sensing modules are temperature and humidity sensor, Light Dependent Resistor (LDR) and rain sensor. The rain sensor is used to detect the present of water. The water will complete the circuit board that has been printed onto the rain sensor. It will act like a variable resistor where the more water on the board, the less the resistance value. This work used a capacitive humidity sensor and the thermistor to measure the surrounding air. It sends the signal to the data pin in digital by changing the total capacitance. This capacitance value is proportional with the humidity value.

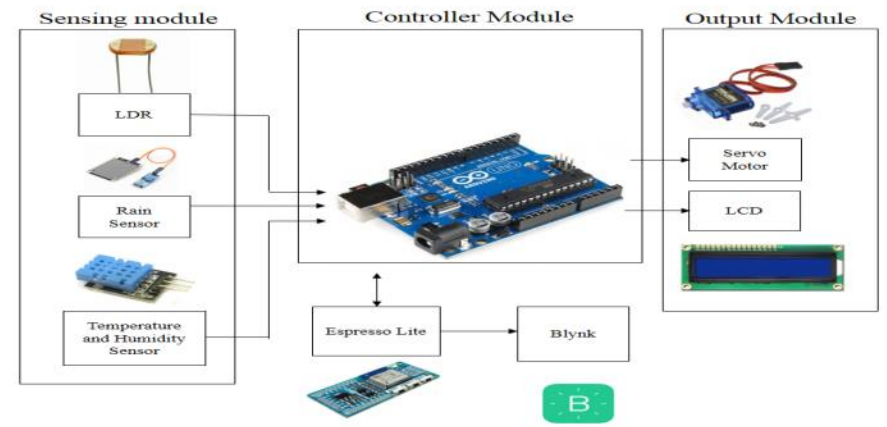

Fig 1: Block diagram of Smart Clothline System

The output module consists of DC motor and liquid crystal display (LCD). The DC motor can rotate until $180^{\circ}$ in total. As the DC motor move, the potentiometer will move as well until shaft reach the desired position. The potentiometer is used to change the value of resistance according dc motor's rotation. Then, the control unit will calculate the movement 
either to the left or to the right. The LCD displays the actual reading of temperature and humidity at the surrounding area

The controller module includes of Arduino Uno and Espresso Lite that was added with the purposes to send the notification to the user via Blynk application. The Arduino UNO act as a microcontroller where it can be programmed by using Arduino IDE software. Arduino UNO has 14 digital input/output pins, USB connection, a power jack, and an ISCP header and reset button. It can be implemented by attach it to the computer with USB cable.

\subsection{Software Design}

Figure 2 shows the schematic diagram that shows the connections between all the components using Proteus software.

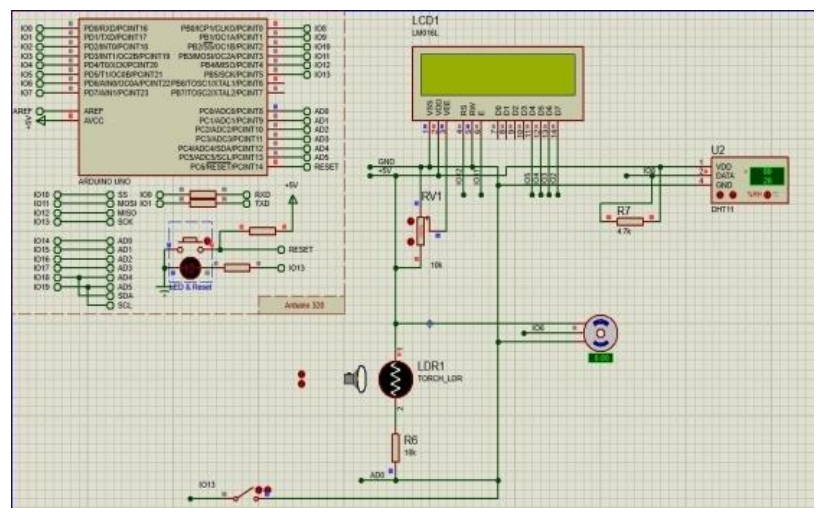

Fig 2: Overall schematic diagram

\subsection{Simulation Design}

The flowchart for the overall system is shown in Figure 3. In default condition, the Smart Cloth Line is originally expanding. Then, the rain sensor will detect the present of water and the LDR used to detect the present of light. Both sensors, LDR and rain sensor used to detect the respective elements. When the sensors detect these elements, it will send input data to the microcontroller, and then the Cloth Line will be compressed. Temperature and humidity sensor is added to add features in this work whereby it will detect the temperature and humidity from the surrounding. The microcontroller, Arduino Uno will coordinate the system by calculating the input from all sensors either to compress or expand the Smart Cloth Line system. Then, the system will send the notification to the user through mobile phone using Blynk application. 


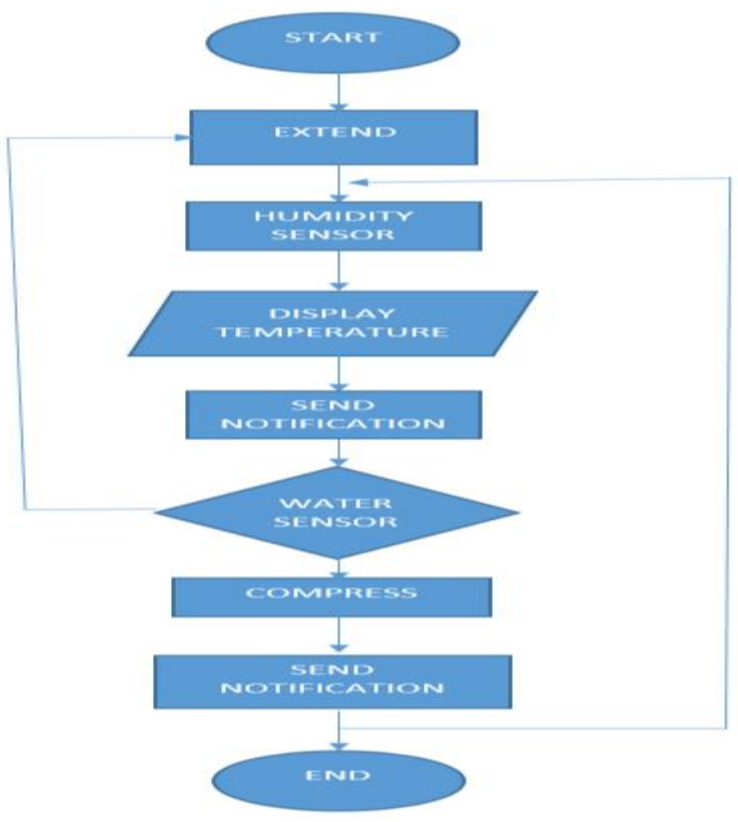

Fig 3: Flowchart for Smart Cloth line system

Arduino programming for the Smart Cloth Line system was done by using $\mathrm{C}++$ programming language. This language consists of two main function which are 1) setup function which is used to initialize variables, initialize the input and output pin modes and other libraries needed in the program. Number 2) is loop function in which function loop is executed in the main program in the repeatedly manner. The example of coding is shown below:

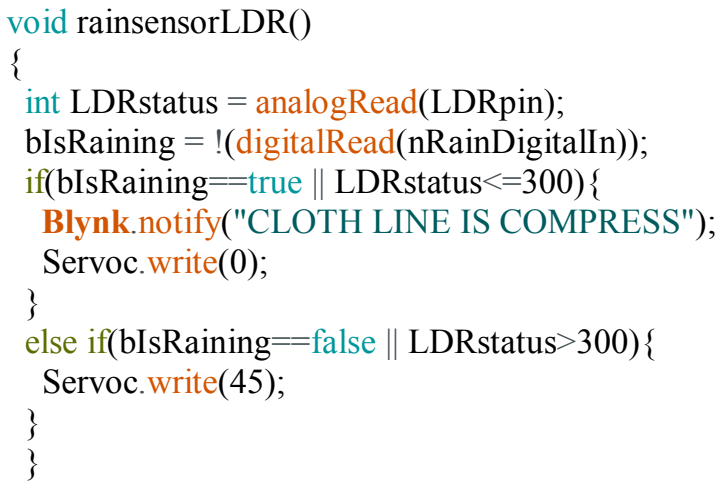

The void is used to read input from LDR and rain sensor. If the condition of rain sensor is true and LDR is below or equal to 300, Arduino will send notification to Blynk app according to the message and the servo is set to $0^{\circ}$. If the other condition is met the servo is set to $45^{\circ}$.

\section{Results and Discussions}

The prototype of Smart Cloth line system is shown in Figure 4. 


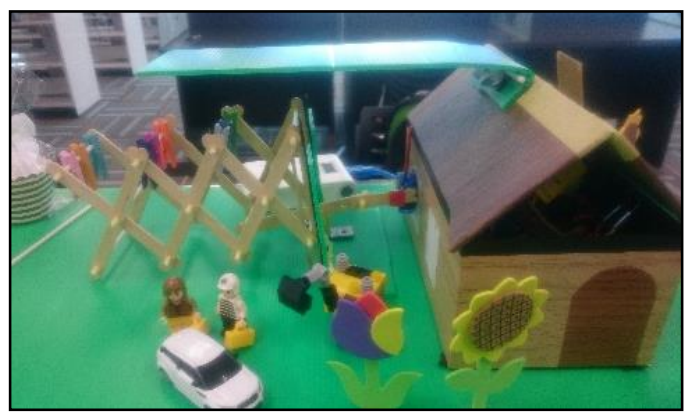

Fig 4: Prototype of Smart Cloth Line System

At first the temperature and humidity sensor detect the surrounding temperature and humidity, then it will be display on the LCD display. If the rain sensor did not detect any presence of water, the servo motor in position $0^{\circ}$ which mean the cloth line is expand as shown in Figure 5. Next is when the rain sensor detects the present of water, so the servo motor moves at angle $45^{\circ}$ which makes the cloth line compress as shown in Figure 6 . Then, LCD shows the actual reading of temperature and humidity from the surrounding as shown in Figure 7.

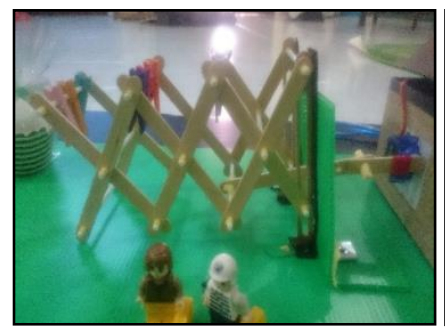

Fig 5: Servo motor at $0^{\circ}$

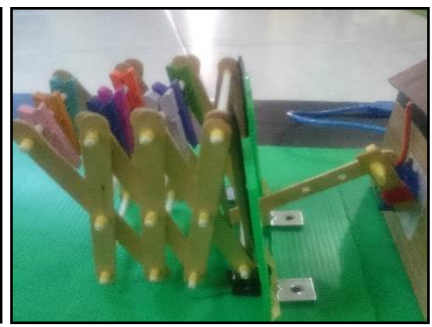

Fig 6: Servo motor at $45^{\circ}$

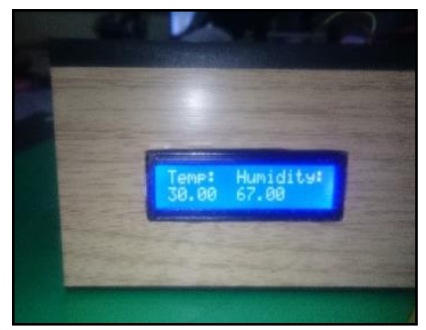

Fig 7: LCD Display

Then, Blynk application will send the notification to the user about the current temperature and humidity as shown in Figure 8.

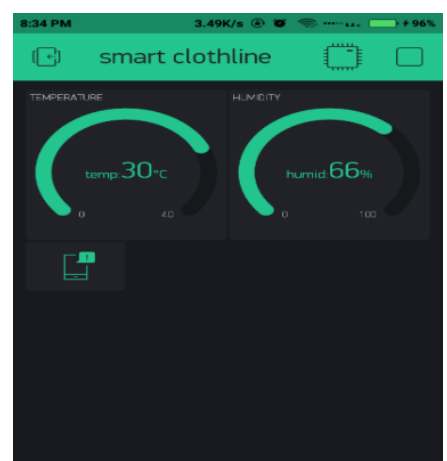

Fig 8a: Blynk displays temperature and humidity

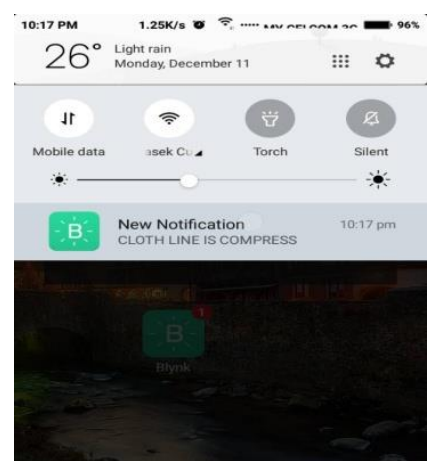

Fig 8b: Blynk send notification 


\section{Conclusions}

This project is proposed as a method to improve the lifestyle of many people as the user can monitor and control the connected device using smartphone. The system which is based on Internet of Thing (IoT) detects the presence of water and light during the rainy day. The system will send the notification to the user through Blynk application. The result shows that the system has been successfully developed and has great potential for future commercialization since many people out there were too busy with their daily life. Thus, this kind of invention can help people to ease their daily life.

We would like to express our gratitude to UiTM Kampus Pasir Gudang and ARAS under project code: 600-IRMI/DANA 5/3/ARAS (0135/2016 for endless support and providing me an opportunity to this project, Smart Cloth Line System. Also thanks to friends for giving me an ideas and suggestions to embark this project. The author would like to express her thanks to the sponsor.

\section{References}

1. B. Davidović and A. Labus, Electronics and Energetics vol. 29, pp. 451-460, (2016).

2. A. Yasirli and S. Mukhammad Andri. IOP Conference Series: Materials Science and Engineering, vol. 325, p. 012021, (2018).

3. H. Ghayvat, et al., "WSN- and IOT-Based Smart Homes and TheirExtension to Smart Buildings," Sensor, vol. 15, pp. 10350-10379, (2015).

4. W. S. Lee and S. H. Hong, "Implementation of a KNX-ZigBee gateway for home automation," presented at the Proceedings of the IEEE 13th International Symposium Consumer Electronics ISCE, (2009).

5. F. Tariq, et al., "Implementation of Smart Homes and Industrial Automation System with Secure Communication over GSM," Universal Journal of Electrical and Electronic Engineering, vol. 3, pp. 125-131, (2015).

6. PanthS and J. M., "Home Automation System (HAS) using Android for Mobile Phone," International Journal of Electronics and Computer Science Engineering (IJECSE), vol. 3, pp. 1-11, (2013).

7. "That 'Internet of Things' thing," RFID J., p. 4986, (2010).

8. "A Review on security in smart home development," Int. J. Adv. Sci. Technol., vol. 15, p. 13, (2010).

9. P. R, et al., "Development of Energy saving smart home prototype," Int. J. Smart Home, vol. 7, pp. 47-77, (2013).

10. P. R and S. R. L, "Smart Home-control and monitoring system using smart phone," in Proc. 1st Int. Conf. Converg. it's Appl. p. 83, (2013).

11. H. S. Bedi, et al., "Smart Trolley using Smart Phone and Arduino," Journal of Electrical \& Electronic Systems, vol. 6, (2017).

12. M. Hidayat, et al., "Implementation of Wireless Sensor Network to reduce cashier queue," in 2014 Makassar International Conference on Electrical Engineering and Informatics (MICEEI), pp. 78-82. (2014) 